\title{
El camino de la heroína Narrativa, género y diversidad Proyecto de Investigación 14.6 Equipo de Investigación
}

Gabriel Los Santos y Tomás Stiegwardt por Facultad de Diseño y Comunicación, Universidad de Palermo (ARG), Marcelo Sabatés, Gabriela Díaz de Sabatés y Carolina Posse Emilianipor Consulate General of Argentina in Chicago (EEUU)

Línea de Investigación 14. Cine y sociedad: Reflexiones sobre el cine contemporáneo

\section{Resultados publicados en el [Cuaderno 117]}

Cuaderno del Centro de Estudios de Diseño y Comunicación No117. (2020/2021) El camino de la heroína: narrativa, género y diversidad. Coordinación Gabriel Los Santos, Tomás Stiegwardt, Marcelo Sabatés, Gabriela Díaz de Sabatés, y Carolina Posse Emiliani. Programa de Investigación de la Facultad de Diseño y Comunicación. Centro de Estudios en Diseño y Comunicación.Facultad de Diseño y Comunicación. Universidad de Palermo. Año XXIV. Buenos Aires, Argentina. ISSN: 1668-0227.

Los resultados de este Proyecto de Investigación fueron evaluados por Javier de Ponti $y$ su Dictamen se transcribe a continuación:

\section{Síntesis de la Evaluación}

Actualidad de la temática (Vigencia, Aplicación) / Notable Nivel Alcanzado (Profundidad, Consistencia, Jerarquía) / Notable Diversidad del enfoques (Pluralidad, Participación) / Notable Calidad (Problemática, Análisis, Tratamiento) / Notable Contribución al avance del Diseño (Fortaleza) / Regular

\section{Fundamentos y Comentarios}

El presente número de Cuadernos se enmarca en la investigación sobre cine contemporáneo y sociedad. Partiendo del análisis de narrativas provenientes de diferentes campos propone una mirada amplia sobre la cuestión de género de cara a una sociedad más respetuosa y diversa. En ellas toma como eje común el sujetoheroico atravesando distintas problemáticas en las que se entrecruza la cuestión de género, la homosexualidad, el feminismo, la representación, la imagen, entre otras. 
La elección de la figura del héroe es un acierto, podría no resultar unívoca y en este sentido abre espacios de discusión, remite a los procesos tanto materiales como simbólicos, da cuenta de los grupos sociales que los erigen. De modo que reflexionar desde el punto de vista crítico sobre quienes son convocados a ese rol salvador invita al pensar sobre los productos audiovisuales que consumimos. La compilación pone en debate una problemática muy vigente a la vez que avanza en la reflexión desde la complejidad que es propia de cadacaso en cuestión. Hay varios trabajos destacados, pero el nivel es parejo, de modo que hacer hincapié en unospodría resultar injusto frente a los demás.

La publicación atraviesa diferentes debates, visiones generales, análisis pormenorizados y abordajes narrativos más globales El ideario del héroe, los géneros y subgéneros del cine, las realizadoras, los personajes, los medios masivos, la historia, la literatura, el baile, son tópicos presentes. A medida que va transcurriendo el texto, el lector podrá inquietarse con sus propias preguntas ¿cuáles son los paradigmas heroicos en nuestra sociedad? ¿Qué clase de distinciones de género residen en ellos? ¿Por qué los aceptamos tal como vienen dados? Hallará algunas respuestas certeras en los textos, pero también nuevas preguntas. En cuanto al aporte al diseño y comunicación, si bien no se trata de trabajos de investigación sobre proyecto, estos escritos pueden resultar disparadores para futuras investigaciones. No solo la cuestión de género en la historia del diseño a través de sus protagonistas, sino también en sus representaciones, en los sistemas de signos señaléticos, institucionales, patrimoniales e informacionales -por nombrar algunos- que constituyen elentorno en el que vivimos, pueden ser objeto de análisis para próximos trabajos. 